\title{
Estimation of oral leukoplakia treatment records in the research of the Department of Maxillofacial and Oral Surgery, Medical University of Gdansk
}

\author{
Anna Starzyńska ${ }^{1}$, Anita Pawłowska ${ }^{1}$, Dorota Renkielska ${ }^{1}$, Igor Michajłowski², Michał Sobjanek ${ }^{2}$, Izabela Błażewicz ${ }^{2}$, \\ Adam Włodarkiewicz ${ }^{1}$
}

'Department of Maxillofacial and Oral Surgery, Medical University of Gdansk, Gdansk, Poland Head of the Department: Prof. Adam Włodarkiewicz MD, PhD

2Department of Dermatology, Venereology and Allergology, Medical University of Gdansk, Gdansk, Poland Head of the Department: Prof. Roman Nowicki MD, PhD

Postep Derm Alergol 2015; XXXII, 2: 114-122 DOI: $10.5114 / p d i a .2014 .40791$

\begin{abstract}
Introduction: Oral leukoplakia (OL) is the most common potentially malignant lesion of the oral cavity. Aim: The purpose of the study was clinical and epidemiological analysis of patients with OL diagnosed and treated in the Department of Maxillofacial and Oral Surgery, Medical University of Gdansk, comparison of effectiveness of treatment methods, defining whether van der Waal level of OL influences treatment effectiveness, correlation between localization of OL and treatment effectiveness, and defining the optimal OL therapeutic method.

Material and methods: Among 55911 patients diagnosed and treated in the Department in the years 1999-2009, 204 people with OL were selected (104 women, 100 men, average age: 58.1 years). Treatment and observation period of 6 months was completed by 178 (87.25\%) patients. Seventy-four patients were treated with cream containing $0.05 \%$ tretinoin. Sixty-three patients underwent cryosurgery, and 41 surgery. Control visits were made in week 2,4 , 6 and 8 and 6 months after completed treatment.

Results: Three hundred and twenty lesions of OL were diagnosed. According to van der Waal classification, the largest group of patients was classified into stage I and II. The percentage of totally cured patients was $90.07 \%$. There were no statistic differences in effectiveness between surgical and cryosurgical treatment.

Conclusions: Evaluation of OL treatment methods depends on localization of the lesions and its stage of progression. The effectiveness of treatment with locally applied tretinoin is smaller in comparison to surgery and cryosurgery. It allows to reduce the number and size of OL lesions, what makes it possible to reduce the number of ablative procedures.
\end{abstract}

Key words: leukoplakia, treatment, tretinoin, cryosurgery, surgical excision.

\section{Introduction}

Oral leukoplakia $(\mathrm{OL})$ is the most common potentially malignant lesion of the oral cavity. The name derives from Greek, and is a combination of the words: $\lambda \varepsilon v \chi 0$ (leuko - white) and $\pi \lambda \alpha \kappa o \sigma$ (plakos - patch). It was first described by Erno Schwimmer in 1877 as a white colored lesion localized on the tongue which was probably connected to syphilis (glossitis syphilitica). Over 30 years ago World Health Organization (WHO) proposed the first OL definition: a white spot or shield which does not correspond clinically or histologically to any other diagnosis and is not caused by action of any physical or chemical agent except of tobacco [1]. During the last 30 years definitions of OL were modified, which complicated the exchange of information between clinicians, pathomorphologists and epidemiologists [2]. Finally, OL is defined as a white shield with an uncertain risk of malignant transformation by excluding other known diseases or disorders that are not connected with an increased risk of cancer [2]. Oral leukoplakia is a clinical diagnosis made by exclusion and it does not have a characteristic histopathological picture or reference to presence/absence of

Address for correspondence: Anna Starzyńska MD, PhD, Department of Maxillofacial and Oral Surgery, Medical University of Gdansk, 17 Smoluchowskiego St, 80-214 Gdansk, Poland, phone: +48 505167 428, fax: +48 583493 100, e-mail: ast@gumed.edu.pl Received: 14.07.2013, accepted: 20.11.2013. 
dysplasia. The term 'leukoplakia' is used as a clinical one (initial and final diagnosis) or histopathological (initial and final diagnosis).

\section{Aim}

The aims of the research were to analyze the evaluation of $\mathrm{OL}$ treatment among patients diagnosed and treated in the Department of Maxillofacial and Oral Surgery, Medical University of Gdansk, defining and comparing the effectiveness of OL treatment methods, assessing whether the stage of van der Waal classification of OL [3] and its location affect treatment results and define optimal treatment methods for OL.

\section{Material and methods}

The study was performed at the Department of Maxillofacial and Oral Surgery, Medical University of Gdansk (Head of the Department: Professor Adam Włodarkiewicz) between 1999 and 2009. Among 55911 patients diagnosed and treated in the Department, 204 patients with OL were selected. The material includes 104 women and 100 men with an average age of 58.1 years. The study was constructed in a retrospective and prospective manner. In the retrospective segment, between the years 1999 and 2004, epidemiological and clinical evaluation of the treatment was performed. However, in this period of time patients with OL were treated solely with cryosurgery or surgery. Prospective studies were conducted in the years 2005-2009. At this time, besides the above-mentioned therapies, topical $0.05 \%$ tretinoin cream was applied. In each case of OL, the diagnosis was confirmed by histopathological examination. Each patient carried out sanitation procedures of the oral cavity in order to eliminate the factors sustaining the disease. The clinical diagnosis involved WHO criteria for potentially malignant disorders and the classification of leukoplakia by Axell and the four-stage classification of van der Waal. The moment of initial presentation of the lesions was noted, special attention was paid to risk factors and concomitant chronic diseases. Photographic documentation was performed using a digital camera (Kodak). A full course of therapy and 6-month follow-up period was completed by 178 patients ( $87.25 \%)$. In case of failure or relapse of OL after topical $0.05 \%$ tretinoin treatment, cryosurgery or surgery was performed. Relapse after cryosurgery treatment was treated again with cryosurgery or was surgically removed.

The choice of the most appropriate method of treatment is difficult and still remains the subject of discussions. Due to the lack of randomized clinical trials there are no widely accepted criteria regarding the treatment of OL. One of the aims of the present study was the attempt to work out a therapeutic algorithm in this disease. Patients were qualified for the specific method of treatment according to the histopathological and clinical stage, localization and extent of lesions. Medical treatment was started with the least invasive method. In cases of the diameter of less than $1 \mathrm{~cm}$, the diagnostic biopsy was at the same time the method of treatment. In cases with the presence of dysplasia one of the ablative methods (cryosurgery or surgery) was suggested. Methods of treatment were talked over with the patient. Informed consent was given to the chosen method of treatment.

Treatment with a cream containing $0.05 \%$ tretinoin (Locacid, Pierre-Fabre) was used in 74 subjects. Patients used the topical specimen on the affected area twice a day. They prolonged its contact with the mucous membranes with occlusive swabs or spatulas. In case of irritation, smearing with 5\% Solcoseryl paste (ICN Polfa Rzeszow) or stopping application for 24-48 h was recommended. Topical treatment was used for at least 8 weeks. Cryosurgery was performed in 63 patients. All procedures were performed under local anesthetic of $2 \%$ lignocaine using Cryo-S engine with nitrous oxide as a cooling medium. All procedures were performed by the spraying method, using two cycles of freezing, each $40 \mathrm{~s}$ in length, with an interval of 2-3 min between them. In the case of multifocal changes, a multi-step approach with 2-3-week intervals between follow-up visits was taken. In case of pain, over the counter non-steroidal anti-inflammatory drugs and 5\% Solcoseryl paste (ICN Polfa Rzeszow) were recommended after the surgery. Forty-one patients underwent surgical treatment. The surgeries were performed under local anesthetic of 2\% lignocaine. Excisions were performed within borders of clinically visible changes. Depending on the location and size of the lesions, cavities were closed in a linear way, covered with a graft or allowed to cover with granulation tissue. Patients were monitored 2, 4, 6 and 8 weeks and then every 6 months. No significant side effects or complications during the treatment which could interrupt the therapy were observed. Regression was assumed when the changes clinically subsided. Partial regression was assumed when at least $50 \%$ of the changes subsided. Other changes were classified as no improvement/relapse. The appearance of new lesions in an adjacent area was regarded as a relapse.

\section{Statistical analysis}

All calculations were performed using the statistical package Statistica 8.0 (StatSoft, Inc. in 2008) and Microsoft Excel 2003. To assess the statistical significance of differences in the results of tests, $\chi^{2}$ was employed (depending on the number of samples and on the expected sample size, an original method of Person, test with Yates' correction or Fisher's exact test were used). In all statistical tests the level of statistical significance was $p<0.05$. 


\section{Results}

The percentage of fully recovered patients was 90.07\% (127 patients). Despite treatment, relapses of OL was observed in 14 patients (9.93\%). Results of treatment of 178 patients with OL are presented in Table 1. Statistically, improvement was higher after cryosurgical treatment $(77.78 \%$ vs. $54.05 \%, p=0.01)$ and surgical treatment $(75.61 \%$ vs. $54.05 \%, p=0.04)$ in comparison to tretinoin treatment. However, there were no statistic differences noticed between surgical and cryosurgical treatment effectiveness.

There were statistically crucial differences $(p=0.002)$ while comparing the effectiveness of treatment (recovery vs. lack of improvement/relapse and partial regression) in three types of treatment methods. Higher effectiveness of cryosurgery and surgery in comparison to local treatment was observed. There were statistically important differences in effectiveness of local treatment methods

Table 1. Comparison of OL treatment results of 178 patients with $\mathrm{OL}$

\begin{tabular}{|c|c|c|c|}
\hline Variables & Remission & $\begin{array}{c}\text { Partial } \\
\text { regression }\end{array}$ & $\begin{array}{c}\text { No } \\
\text { improvement/ } \\
\text { relapses }\end{array}$ \\
\hline Tretinoin & $40(54.05)$ & $22(29.73)$ & $12(16.22)$ \\
\hline Cryotherapy & $49(77.78)$ & & $14(22.22)$ \\
\hline Surgery & 31 (75.61) & & $10(24.39)$ \\
\hline
\end{tabular}

Results presented as n (\%). depending on the lesion localization. In the case of lesions localized on the lower gingiva or buccal mucosae, remission occurred more often after cryosurgery and surgery in comparison to local tretinoin treatment $(p=0.05$ and $p=0.03$ ). Lesions localized on the upper gingiva had better response to treatment by cryosurgery as opposed to tretinoin and surgery $(p=0.01)$. Analyzing effectiveness of a particular treatment method according to van der Waal classification and based on histopathological picture, statistically important differences were observed. Improvement occurred more often after cryosurgery and surgery in I level $(p=0.0007)$ in comparison to tretinoin. Comparing treatment results in smoking and non-smoking groups, statistically important differences were observed. In the smoking group, improvement was much more rare with tretinoin treatment $(p=0.003)$ in comparison to cryosurgery ( $44.23 \%$ vs. $65.52 \%$ ) and surgery (4.23\% vs. 68.18\%) (Table 2).

Analyzing $0.05 \%$ tretinoin treatment effectiveness according to van der Waal classification based on the clinical and histological picture, no statistically important differences were observed (Tables 3, 4).

In over $77 \%$ of patients treated with tretinoin, total improvement was observed after 4 weeks of treatment time. In 22 patients (28.57\%) who represented partial or total improvement, after interruption of treatment (on average after 3 months) relapses were observed (Figures 1-3). The results of cryosurgery are presented in Table 5.

Analyzing effectiveness of treatment according to van der Waal OL level based on the histological picture,

Table 2. Percentage disposition of tretinoin treatment according to lesion localization

\begin{tabular}{lcccc}
\hline Localization & Cure & Partial regression & No improvement/relapses & Total \\
\hline Cheek & $49(57.6)$ & $21(24.7)$ & $15(17.6)$ & 85 \\
\hline Floor of the mouth & $7(70.0)$ & $3(30.0)$ & $0(0.0)$ & 10 \\
\hline Tongue & $9(100.0)$ & $0(0.0)$ & $0(0.0)$ & 9 \\
\hline Lower gingiva & $19(50.0)$ & $12(31.6)$ & $7(18.4)$ & 38 \\
\hline Upper gingiva & $2(22.2)$ & $7(77.8)$ & $0(0.0)$ & 9 \\
\hline Lip & $1(50.0)$ & $1(50.0)$ & $0(0.0)$ & 2 \\
\hline Total & 87 & 44 & 22 & 153 \\
\hline
\end{tabular}

Table 3. Results of $0.05 \%$ tretinoin (cream) treatment according to van der Waal OL level based on the histological picture

\begin{tabular}{lcccc}
\hline Level & Cure & Partial regression & No improvement/relapse & Total \\
\hline I & $33(53.2)$ & $20(32.3)$ & $9(14.5)$ & 62 \\
\hline II & $18(72.0)$ & $7(28.0)$ & $0(0.0)$ & 25 \\
\hline III & $34(54.8)$ & $24(38.7)$ & $4(6.5)$ & 62 \\
\hline IV & $2(50.0)$ & $2(50.0)$ & $0(0.0)$ & 4 \\
\hline Total & 87 & 53 & 13 & 153 \\
\hline
\end{tabular}


Table 4. Results of $0.05 \%$ local tretinoin treatment according to van der Waal OL level and histological picture

\begin{tabular}{lcccc}
\hline Level & Cure & Partial regression & No improvement/relapse & Total \\
\hline I & $47(54.0)$ & $31(35.6)$ & $9(10.3)$ & 87 \\
\hline II & $27(62.8)$ & $16(37.2)$ & $0(0.0)$ & 43 \\
\hline III & $13(61.9)$ & $4(19.0)$ & $4(19.0)$ & 21 \\
\hline IV & $1(50.0)$ & $1(50.0)$ & $0(0.0)$ & 2 \\
\hline Total & 88 & 52 & 13 & 153 \\
\hline
\end{tabular}
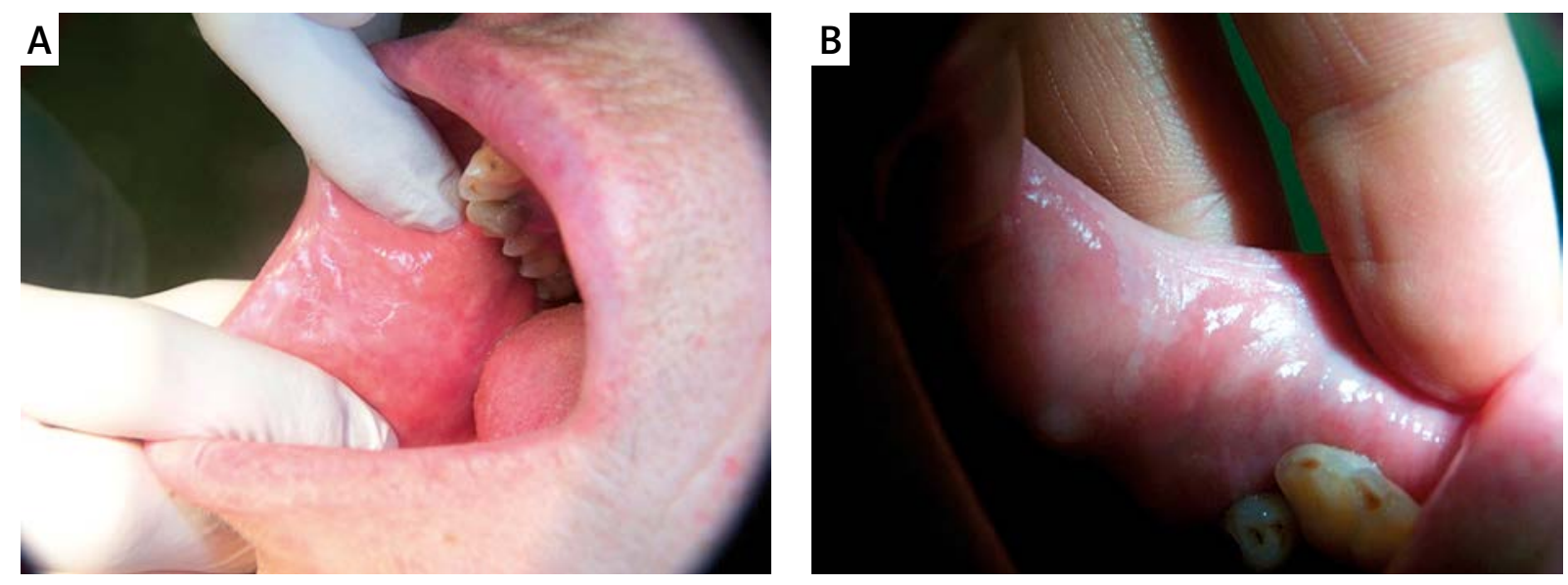

Figure 1 A-B. Heterogenic OL of buccal mucosae. The patient treated with tretinoin for 3.5 months. Partial remission was observed after 1 week of treatment, total remission after 2 months of treatment

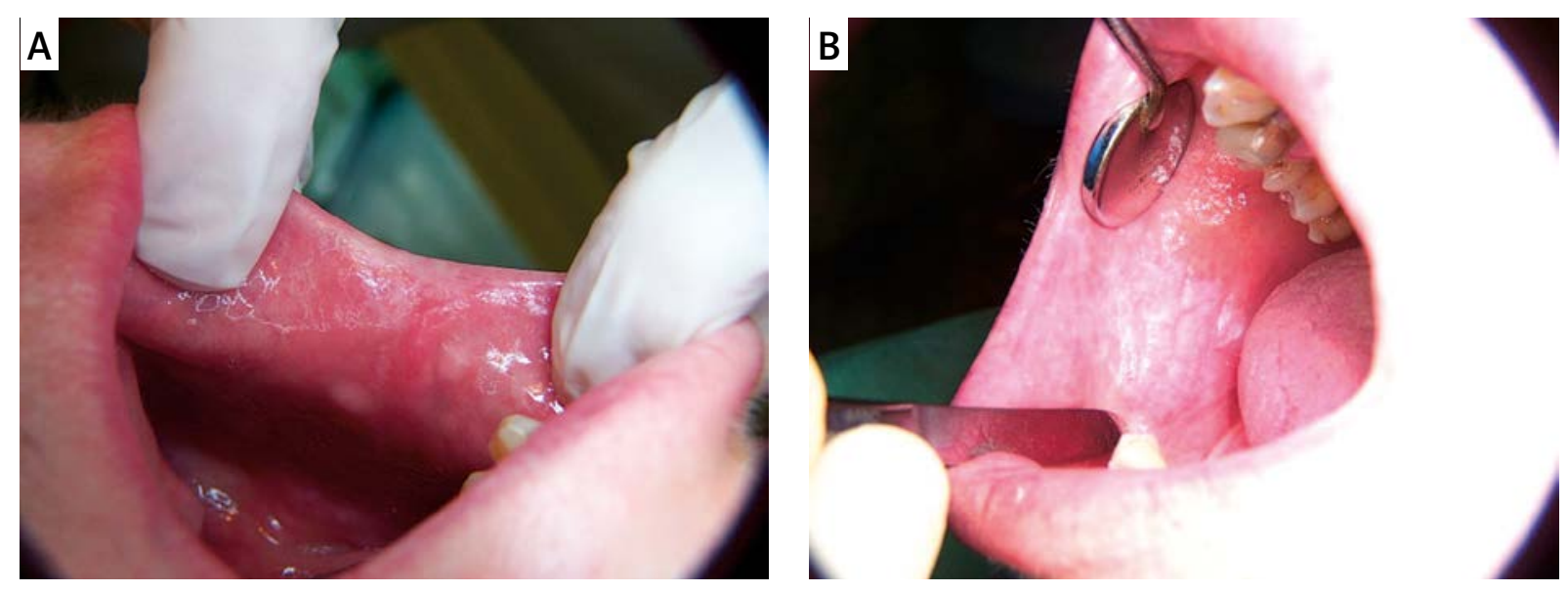

Figure 2 A-B. Homogenic OL of buccal mucosae. After 7 months of tretinoin treatment only partial regression of lesions was observed. The patient was treated by cryosurgery afterwards

statistically significant differences were observed. Statistically, relapses were observed more rarely in level I in comparison to other levels $(p=0.004)$. In case of level III and IV - relapses were observed more often in comparison to other levels ( $p=0.05$ and $p=0$ T02) (Table 6).

Analyzing effectiveness of cryosurgery according to van der Waal classification based on the histological picture, no statistically significant differences were observed
(Table 7). The results of surgical treatment are presented in Table 8.

Analyzing effectiveness of surgical treatment according to van der Waal classification based on the clinical picture there were no statistically significant differences observed (Table 9). Analyzing surgical treatment of OL classification and histological picture, statistically significant differences were observed $(p=0.05)$ (Table 10). 

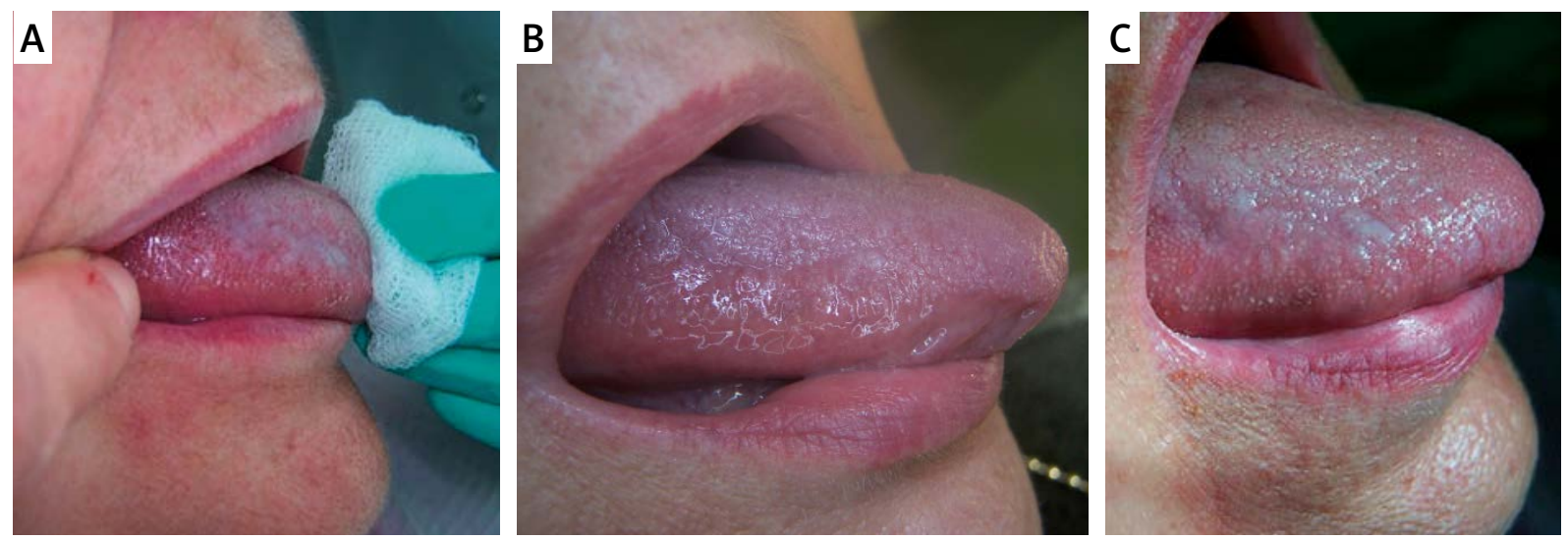

Figure $3 \mathrm{~A}-\mathrm{C}$. Homogenic OL of tongue. Recovery after 3 months of tretinoin treatment. Lesion relapses occurred 3 months after the end of therapy. Cryosurgery was utilized afterwards

Table 5. Results of cryosurgical treatment according to lesion localization. Differences statistically significant

\begin{tabular}{lcc}
\hline Localization & Relapse & Cure \\
\hline Cheek & $14(23.3)$ & $46(76.7)$ \\
\hline Floor of the mouth & $3(27.3)$ & $8(72.7)$ \\
\hline Tongue & $1(12.5)$ & $7(87.5)$ \\
\hline Lower gingiva & $3(18.8)$ & $13(81.3)$ \\
\hline Upper gingiva & $2(18.2)$ & $9(81.8)$ \\
\hline General & $2(100.0)$ & $0(0.0)$ \\
\hline Palate & $0(0.0)$ & $3(100.0)$ \\
\hline Total & 25 & 86 \\
\hline
\end{tabular}

Table 7. Results of cryosurgical treatment according to van der Waal OL level and histological picture

\begin{tabular}{lcc}
\hline Level & Relapse & Cure \\
\hline I & $13(20.0)$ & $52(80.0)$ \\
\hline II & $11(27.5)$ & $29(72.5)$ \\
\hline III & $3(50.0)$ & $3(50.0)$ \\
\hline IV & & \\
\hline Total & 27 & 84 \\
\hline
\end{tabular}

\section{Discussion}

Over 60 years have passed since the first attempts of using vitamin A and its derivatives in OL treatment were introduced [4]. Since then knowledge about these conjunctions has broadened, enabling the application of them in treatment of many other diseases. However, objective estimation of long-term oral use of retinoids in pre- and neoplastic treatment of lesions is difficult
Table 6. Results of cryosurgical treatment according to van der Waal OL level based on the clinical picture

\begin{tabular}{lcc}
\hline Level & Relapse & Cure \\
\hline I & $9(16.1)$ & $47(83.9)$ \\
\hline II & $9(23.7)$ & $29(76.3)$ \\
\hline III & $6(46.2)$ & $7(53.8)$ \\
\hline IV & $3(75.0)$ & $1(25.0)$ \\
\hline Total & 27 & 84 \\
\hline
\end{tabular}

Table 8. Results of surgical treatment according to lesion localization

\begin{tabular}{lcc}
\hline Localization & Relapse & Cure \\
\hline Cheek & $6(26.1)$ & $17(73.9)$ \\
\hline $\begin{array}{l}\text { Floor of the oral } \\
\text { cavity }\end{array}$ & $1(33.3)$ & $2(66.7)$ \\
\hline Tongue & $1(20.0)$ & $4(80.0)$ \\
\hline Lower gingival & $1(12.5)$ & $7(87.5)$ \\
\hline Upper gingival & $4(80.0)$ & $1(20.0)$ \\
\hline Palate & $0(0.0)$ & $1(100.0)$ \\
\hline Lip & $0(0.0)$ & $5(100.0)$ \\
\hline Total & 13 & 37 \\
\hline
\end{tabular}

because of its disadvantageous side effects. Therefore, derivative substances of vitamin A - without these side effects are being searched for [5]. Local application of the substances mentioned above is far more accepted by patients. Until today, there have been only 5 studies which refer to effectiveness of locally used tretinoin in $\mathrm{OL}$ treatment [6-10]. US researchers [6] applied 13-cis-retinoid acid (isotretinoin) in 11 patients with histologically 
Table 9. Results of surgical treatment according to van der Waal classification and clinical picture

\begin{tabular}{lcc}
\hline Level & Relapse & Cure \\
\hline I & $7(22.6)$ & $24(77.4)$ \\
\hline II & $4(40.0)$ & $6(60.0)$ \\
\hline III & $2(22.2)$ & $7(77.8)$ \\
\hline IV & - & - \\
\hline Total & 13 & 37 \\
\hline
\end{tabular}

confirmed OL. After 6 months of treatment full regression was observed in $27 \%$ and partial regression in $54 \%$ of patients. Lesions relapsed in $90 \%$ of patients in 11 months' observation follow-up. Epstein and Gorsky [7] applied $0.05 \%$ tretinoin gel in 26 patients with OL. Gel was used 4 times a day for 3.5 years. In comparison to the research mentioned above, percentages of full and partial lesion regression were identical, however, relapses of OL were undoubtedly lower - approximately $40 \%$ in 3 years' time observation. Side effects which included mucosae irritation in the area of application were observed in 19\% of patients. Even lower effectiveness of locally applied retinoids was observed by Italian researchers in two following reports [8, 9]. In both publications $0.1 \%$ isotretinoin was applied for 4 months. According to the authors, total regression was observed in $10-21.5 \%$. In the rest of the patients the remission was only partial. Poveda-Roda et al. [10] estimated effectiveness of vitamin A derivatives in proliferative verrucous OL treatment. The effectiveness of locally applied $0.1 \%$ isotretinoin gel was approximately $30 \%$. In our study, OL treatment with $0.05 \%$ tretinoin cream was performed in 74 patients $(41.6 \%$ of all treated patients). The total number of treated OL was 153 . The specimen was applied 2 times a day after rinsing and drying the oral mucosae (minimum 8 weeks). Total regression was observed in $54.05 \%$ of treated patients, partial regression of OL in $29.73 \%$. Therapy occurred to be ineffective in $16.22 \%$ of patients. After unsuccessful retinoid treatment, cryosurgery was employed. In over $77.78 \%$ of patients with total regression, the tretinoin
Table 10. Results of surgical treatment according to van der Waal classification based on the histological picture. Statistically relapse is more often in level III $(p=0.01)$

\begin{tabular}{lcc}
\hline Level & Relapse & Cure \\
\hline I & $7(20.0)$ & $28(80.0)$ \\
\hline II & $2(22.2)$ & $7(77.8)$ \\
\hline III & $4(66.7)$ & $2(33.3)$ \\
\hline IV & - & - \\
\hline Total & 13 & 37 \\
\hline
\end{tabular}

treatment effect was noticed on average after 4 weeks of therapy. In 22 patients (28.57\%) with total or partial improvement, relapses were noticed after 3 months from discontinuation of the therapy.

Results of studies on locally applied retinoids in OL treatment are shown in Table 11.

In the presented studies, total regression of OL occurred in about $40 \%$, while partial regression in $46 \%$ of patients. In the rest of patients (14\%) therapy was ineffective. In our study the effectiveness of OL treatment was higher in comparison to the other authors' studies. In our material, the majority of patients had homogenic OL without dysplasia. This fact may be responsible for lower relapse percentage after the treatment. In case of ineffectiveness of the above therapy we performed invasive procedures.

Cryosurgery is a method of treatment which involves controlled tissue damage caused by low temperatures. First reports concerning cryosurgery as a method of treatment date back to about 50 years ago [11]. Up to now there have been many studies published evaluating the effectiveness and safety of cryosurgery [12]. It appears that vascular lesions and potentially malignant lesions of the oral cavity epithelium are a reasonable indication for choosing this method of treatment $[13,14]$. The choice of cryosurgical methods in the treatment of OL depends on the depth, area, and shape of the pathological lesion, as well as on access to cryosurgical equipment and operator's experience [15]. The most popular techniques of cryodestruction by liquid nitrogen $(N)$ are:

Table 11. Studies results of OL treatment with retinoids

\begin{tabular}{lccccc}
\hline Authors (country) & $\begin{array}{c}\text { Number of } \\
\text { patients }\end{array}$ & $\begin{array}{c}\text { Total regression } \\
\text { of lesions (\%) }\end{array}$ & $\begin{array}{c}\text { Partial regression } \\
\text { of lesions (\%) }\end{array}$ & $\begin{array}{c}\text { Relapse of lesions } \\
\text { (\%) }\end{array}$ & $\begin{array}{c}\text { Observation } \\
\text { period [months] }\end{array}$ \\
\hline Italy [63] & 14 & $3(21.5)$ & $11(78.5)$ & $?$ & 4 \\
\hline Italy [62] & 10 & $1(10)$ & $9(90)$ & $?$ & 4 \\
\hline Canada [61] & 26 & $7(27)$ & $14(54)$ & 40 & 90 \\
\hline United States [60] & 11 & $3(27)$ & $6(54)$ & $?$ & $?$ \\
\hline Poland & 74 & $40(54)$ & $22(30)$ & & \\
\hline Total & 135 & $54(40)$ & $62(46)$ & & $?$ \\
\hline
\end{tabular}


freezing with swabs (deep steak), open or closed spraying methods and cryoapplicators [16]. When dinitrogen dioxide $\left(\mathrm{N}_{2} \mathrm{O}_{2}\right)$ is applied, open or closed spraying methods and cryoapplicators can be used. Deep steak method can be administered only in shallow or benign lesions [17]. Modification of the deep steak method might be by putting swabs on an open source of $\mathrm{N}_{2} \mathrm{O}_{2}$, what enable deep, however not precise freezing. Advantage of this method is ability of setting adequate intensity of $\mathrm{N}_{2} \mathrm{O}_{2}$ stream, what enables better control of the freezing area, increases precision of treatment and reduces damage to surrounding tissue. The spraying method involves liquid $\mathrm{N}$ and $\mathrm{N}_{2} \mathrm{O}_{2}$. Liquid $\mathrm{N}$ stream is placed $1.0-1.5 \mathrm{~cm}$ from the treatment area, $\mathrm{N}_{2} \mathrm{O}_{2}-0.5 \mathrm{~cm}$. This method is used in very superficial lesions, while a part of damaged area becomes defrosted during freezing time. To make this method more precise, a closed spraying method can be used which involves cone-shaped and cylinder-shaped covers. In our study cryosurgical treatment of OL was performed in 63 patients. Cryodestruction was applied by the spraying method using $\mathrm{N}_{2} \mathrm{O}_{2}$. Freezing exposition time was dependent on the size of the lesions (average $40 \mathrm{~s}$ ). After defrosting time, $\mathrm{N}_{2} \mathrm{O}_{2}$ spraying was reapplied. Cryoapplicators allow the treatment of lesions ranging in size from $1 \mathrm{~mm}$ to a few $\mathrm{cm}$. The freezing surface of the cryoapplicator is usually circle-shaped (it can be also cone- or needle-shaped). In this method, initial applicator cooling of the cryoapplicator and applying pressure over the exposed tissues, can be considered. Adequate diameter should be chosen, estimation of the freezing area and defrosting time should be defined $[14,18]$. When the largest lesion size is bigger than the tip of the cryoapplicator, methods of overlaying areas should be induced. Effectiveness of therapy depends on adequate freezing time and proper freezing depth. In the case of superficial lesions, clinical manual examination and measurement of freezing/defrosting time seems to be sufficient. In deeper lesions manual assessment does not ensure adequate precision. Assessment based on observation of temperature transmission in tissues appears to be helpful in such cases. The so-called ice front area is crucial. It is a margin of frozen tissue that surrounds the tip of the applicator. It is assumed that its width equals the depth of freezing and its ratio is close to $1: 1.3$. However, some authors pay attention to the fact that this dependence is not constant and depends on freezing technique, shape of the applicator, applied pressure as well as the tissue type. The proportion of freezing/unfreezing tissue time should be equal and at least $1: 2$. Unfreezing time should not be shortened due to the fact that this is the moment when inside-cell damage is made. In the presented study 111 lesions were cryodestructed. More than half of them (53.2\%) were localized on the buccal mucosae. Total regression was observed in 49 patients (77.8\%), lack of improvement in 14 patients (21.2\%). In analyzing relapses and total regression of $\mathrm{OL}$ lesions, the tongue occurred to be the place where the largest percentage of healing was observed (85.7\%). In the gingiva it was $81.5 \%$ and in the buccal mucosae, it was $76.3 \%$. Relapses of OL were observed most often on the floor of the mouth. Analyzing effectiveness of OL treatment according to van der Waal clinical scale, relapses of stage I statistically occurred more rarely than the others, however this dependence was observed according to the histological scale. The advantage of cryosurgery in comparison to local application of retinoids is the permanent destruction of $\mathrm{OL}$ lesions. Furthermore, newly rebuilt epithelium is less likely to become corneous again. Gwiazda-Chojak et al. [14] treated cryosurgically 30 patients with histopathologically confirmed OL. The freezing agent was liquid N, closed and adequately shaped cryoapplicators were used. The time of cryoapplication ranged from 5 to $30 \mathrm{~s}$. One therapeutic session consisted of two or three freezing/ unfreezing cycles (deep freezing was induced). Treatment effectiveness was 100\%. Similar results are published by Romankiewicz [19] and Dawiec et al. [18]. In Waśkowska et al.'s study [20], the percentage of full remissions was about $90 \%$. The authors mentioned above indicate that the reason for $\mathrm{OL}$ reoccurrence was probably continued smoking. Sako et al. [21] report cryosurgery effectiveness of about $80 \%$. In conclusion, the estimation of cryosurgical effectiveness in the treatment of $\mathrm{OL}$ is quite problematic because of the use of different methods and different freezing agents by particular authors. Cryosurgical effectiveness is high and ranges from $80 \%$ to $100 \%$.

Surgical treatment still remains one of the most common treatment methods in OL and should be the method of choice in OL with histologically diagnosed epithelial dysplasia [22, 23]. The hypothesis stating that surgical removal of a potentially malignant lesion decreases the chances of occurrence of oral squamous cell carcinoma (OSCC) remains still unconfirmed [12]. While speaking of invasive treatment of $\mathrm{OL}$, it should be indicated that most of excisions were made by lasers (especially $\mathrm{CO}_{2}$ and $\mathrm{Nd}$ :YAG) [24-30]. In the mentioned publications, total laser vaporization of tissues was performed. In other studies, laser excision with consecutive histological examination was described. Studies with classic surgical excision were carried out more seldom. Total laser vaporization makes histological examination of lesions impossible, this is crucial in the case of dysplasia. Chandu and Smith [24] presented a study of 69 treated OL lesions. Relapses were observed in approximately half of the cases. An even higher risk of relapses, of about 57.1\%, is reported by Flynn et al. [28]. According to the authors, laser vaporization can be considered as a good treatment method in OL without dysplasia.

This method can be applied in treating multifocal OL as well as larger areas of OL. This makes it superior to the classic surgical excision. In the case of laser therapy the risk of relapses is also much lower. Chiesa et al. [25] observed the lowest rate of relapses $-3.7 \%$. The other 
authors report $10-17.8 \%[26,31,32]$. In the treatment of OL with dysplasia this method is appropriate.

The classic OL excision has been estimated in some studies [33, 34]. Holmstrup et al. described 89 patients who had surgical excision of their lesions performed. In 6.8 years of observation, relapses were observed in $13.5 \%$. The author treated 53 patients. In 12 months of observation, relapses were noticed in $17 \%$ of patients. In our study, surgical treatment was performed in $41 \mathrm{pa}-$ tients (23\% of all treated patients). Fifty lesions of OL were totally removed. Relapses were observed in $24.4 \%$ of patients. Statistically relapses were observed more often in lesions located on the upper gingiva.

Concluding, the risk of relapse of lesions in the case of classic surgical treatment is approximately $20 \%$, making it comparable to cryosurgery. Taking into consideration that all lesions qualified for traditional surgical treatment had features of epithelial dysplasia and were nonhomogenous. This automatically placed them in the highest risk of relapse rate irrespective of the applied method. Traditional surgery should be considered a more effective treatment method than cryosurgery. It is worth mentioning that every patient treated because of OL should undergo control examinations because up to now there has been no method that can prevent invasive OSCC in all cases.

Analyzing results of $\mathrm{OL}$ treatment with described three methods, local tretinoin treatment can be considered as a good choice in homogenic OL without dysplasia or as an initial treatment in other cases of OL. In case of no improvement, treatment should become more invasive. Cryosurgery and surgery can be applied as a substitution therapy in every case of OL with dysplasia. Relapses or no improvement after any form of treatment is associated with tobacco use. These relapses are situated in the areas neighboring the treated places. This observation supports the concept of multifocal carcinogenesis in the flat epithelium of the oral cavity.

\section{Conclusions}

Effectiveness of locally applied tretinoin is smaller than surgery and cryosurgery in OL treatment. However, tretinoin enables reduction in size and number of lesions, which reduces the number of ablative procedures. Results of OL treatment depend on lesion localization and its clinical stage. Tobacco smoking is the most important patient-dependent factor which influences treatment effectiveness. Combination treatment of $\mathrm{OL}$ is an interesting therapeutic option.

\section{Conflict of interest}

The authors declare no conflict of interest.

\section{References}

1. Kramer IR, Lucas RB, Pindborg JJ, et al. Definition of leukoplakia and related lesions: an aid to studies on oral precancer. Oral Surg Oral Med Oral Pathol 1978; 46: 518-39.
2. Warnakulasuriya S, Johnson NW, van der Waal I. Nomenclature and classification of potentially malignant disorders of the oral mucosa. J Oral Pathol Med 2007; 36: 575-80.

3. Starzyńska A, Pawłowska A, Renkielska D, et al. Oral premalignant lesions: epidemiological and clinical analysis in the northern Polish population. Postep Derm Alergol 2014; 31: 341-50.

4. Mulay DN, Urbach F. Local therapy of oral leukoplakia with vitamin A. AMA Arch Dermatol 1958; 78: 637-8.

5. Khuri FR, Lippman SM, Spitz MR, et al. Molecular epidemiology and retinoid chemoprevention of head and neck cancer. J Natl Cancer Inst 1997; 89: 199-211.

6. Shah JP, Strong EW, DeCosse JJ, et al. Effect of retinoids on oral leukoplakia. Am J Surg 1983; 146: 466-70.

7. Epstein JB, Gorsky M. Topical application of vitamin A to oral leukoplakia: a clinical case series. Cancer 1999; 86: 921-7.

8. Piattelli A, Fioroni M, Santinelli A, et al. Bcl-2 expression and apoptotic bodies in 13-cis-retinoic acid (isotretinoin)-topically treated oral leukoplakia: a pilot study. Oral Oncol 1999; 35: 314-20.

9. Tetè S, Pappalardo S, Rubini C, et al. The role of apoptosis and bcl-2 protein in topical treatment of oral leukoplakia with isotretinoin. Minerva Stomatol 1999; 48: 411-8.

10. Poveda-Roda R, Bagan JV, Jiménez-Soriano Y, et al. Retinoids and proliferative verrucous leukoplakia (PVL). A preliminary study. Med Oral Patol Oral Cir Bucal 2010; 15: 3-9.

11. Emmings FG, Koepf SW, Gage AA. Cryotherapy for benign lesions of the oral cavity. J Oral Surg 1967; 25: 320-6.

12. Lodi G, Porter S. Management of potentially malignant disorders: evidence and critique. J Oral Pathol Med 2008; 37: 63-9.

13. Ishida CE, Ramos-e-Silva M. Cryosurgery in oral lesions. Int J Dermatol 1998; 37: 283-5.

14. Gwiazda-Chojak E, Bednarz I, tysiak K, et al. Usage of liquid nitrogen in treatment of haemangiomas and leukoplakia of the mucosae of the oral cavity, lips and tongue. Dent Med Probl 2005; 42: 59-64.

15. Dawber R. Cryosurgery: unapproved uses, dosages, or indications. Clin Dermatol 2002; 20: 563-70.

16. Sinclair RD, Dawber RP. Cryosurgery of malignant and premalignant diseases of the skin: a simple approach. Australas J Dermatol 1995; 36: 133-42.

17. Yu CH, Chen HM, Chang CC, et al. Cotton-swab cryotherapy for oral leukoplakia. Head Neck 2009; 31: 983-8.

18. Dawiec G, Dziadek H, Kożdoń K, et al. Cryotherapy usage in oral surgery. Ann Soc Doctr Acad Med Siles 2000; 26: 251-8.

19. Romankiewicz P. Cryosurgery in treatment of particular oral mucosae and skin diseases. Porad Stomatol 2002; 8: 13-6.

20. Waśkowska J, Koszowski R. Assesment of cryosurgical treatment of oral leukoplakia in material of Departament of Oral Surgery Mediacal University of Slask. Czas Stomatol 2006; 6: 438-45.

21. Sako K, Marchetta FC, Hayes RL. Cryotherapy of intraoral leukoplakia. Am J Surg 1972; 124: 482-4.

22. Brennan M, Migliorati CA, Lockhart PB, et al. Management of oral epithelial dysplasia: a review. Oral Surg Oral Med Oral Pathol Oral Radiol Endod 2007; 103 Suppl: S19. e1-12.

23. Van der Waal I. Potentially malignant disorders of the oral and oropharyngeal mucosa; terminology, classification and present concepts of management. Oral Oncol 2009; 45: 317-23.

24. Chandu A, Smith AC. The use of CO2 laser in the treatment of oral white patches: outcomes and factors affecting recurrence. Int J Oral Maxillofac Surg 2005; 34: 396-400. 
25. Chiesa F, Sala L, Costa L, et al. Excision of oral leukoplakia by $\mathrm{CO} 2$ laser on an out-patient basis: a useful procedure for prevention and early detection of oral carcinomas. Tumori 1986; 72: 307-12.

26. Chu FW, Silverman S Jr, Dedo HH. CO2 laser treatment of oral leukoplakia. Laryngoscope 1988; 98: 125-30.

27. Frame JW, Das Gupta AR, Dalton GA, et al. Use of the carbon dioxide laser in the management of premalignant lesions of the oral mucosa. J Laryngol Otol 1984; 98: 1251-60.

28. Flynn MB, White M, Tabah RJ. Use of carbon dioxide laser for the treatment of premalignant lesions of the oral mucosa. J Surg Oncol 1988; 37: 232-4.

29. Schoelch ML, Sekandari N, Regezi JA, et al. Laser management of oral leukoplakias: a follow-up study of 70 patients. Laryngoscope 1999; 109: 949-53.

30. Thomson PJ, Wylie J. Interventional laser surgery: an effective surgical and diagnostic tool in oral precancer management. Int J Oral Maxillofac Surg 2002; 31: 145-53.

31. Roodenburg JL, Panders AK, Vermey A. Carbon dioxide laser surgery of oral leukoplakia. Oral Surg Oral Med Oral Pathol 1991; 71: 670-4.

32. van der Hem PS, Nauta JM, van der Wal JE, et al. The results of CO2 laser surgery in patients with oral leukoplakia: a 25 year follow up. Oral Oncol 2005; 41: 31-7.

33. Holmstrup P, Vedtofte P, Reibel J, et al. Long-term treatment outcome of oral premalignant lesions. Oral Oncol 2006; 42: 461-74.

34. Pandey M, Thomas G, Somanathan T, et al. Trivandrum Oral Cancer Screening Study Group. Evaluation of surgical excision of non-homogeneous oral leukoplakia in a screening intervention trial, Kerala, India. Oral Oncol 2001; 37: 103-9. 